\title{
Effect of Assignment Choice on Student Academic Performance in an Online Class
}

\author{
Hannah MacNaul ${ }^{1,2}$ (D) Rachel Garcia $^{2}$ (D) Catia Cividini-Motta ${ }^{2}$ (D) Ian $_{\text {Thacker }}{ }^{1}$ (])
}

Accepted: 10 February 2021 / Published online: 26 February 2021

(C) Association for Behavior Analysis International 2021

\begin{abstract}
Choice of assignment has been shown to increase student engagement, improve academic outcomes, and promote student satisfaction in higher education courses (Hanewicz, Platt, \& Arendt, Distance Education, 38(3), 273-287, 2017). However, in previous research, choice resulted in complex procedures and increased response effort for instructors (e.g., Arendt, Trego, \& Allred, Journal of Applied Research in Higher Education, 8(1), 2-17, 2016). Using simplified procedures, the current study employed a repeated-measures with an alternating-treatments design to evaluate the effects of assignment choice (flash cards, study guide) on the academic outcomes of 42 graduate students in an online, asynchronous course. Slight differences between conditions were observed, but differences were not statistically significant.
\end{abstract}

Keywords Choice $\cdot$ Online education $\cdot$ Graduate students $\cdot$ Academic performance

As access to the internet increases, more students pursuing higher education are completing online programs. In fact, nearly $50 \%$ of master's-level applied behavior analysis training programs in the United States offer courses in an online format (Behavior Analyst Certification Board, 2021). Given the increase of students in online courses and programs, investigating instructional procedures to support students in meeting learning outcomes has become critical. In learner-

\section{Research Highlights}

- The Canvas Mastery Paths function allows instructors to automate choice of assignments into a course, as well as differentiate instruction across students.

- This study extends our understanding of effective teaching strategies in online instruction because results demonstrated that choice of assignments alone did not significantly improve student learning outcomes.

- In this study, choice of assignment was designed in a manner to allow feasibility of implementation by most instructors.

- This article includes step-by-step instructions for how to use the Canvas Mastery Paths function, provided as online Supplementary Material.

Hannah MacNaul

Hannah.MacNaul@utsa.edu

1 Department of Educational Psychology, University of Texas at San Antonio, San Antonio, TX 78207, USA

2 Department of Child and Family Studies, University of South Florida, Tampa, FL, USA centered teaching (LCT; Weimer, 2013), instructors aim to motivate students by giving them some control over the learning process, such as choice of assignments and choice of assignment deadlines.

In the academic context, the opportunity to select between two or more concurrently available assignments has been shown to increase student engagement, exam scores, and student satisfaction (e.g., Hanewicz et al., 2017). Moreover, various assignment formats - that is, flash cards and study guides - are empirically supported strategies that help students build fluency with material and improve efficiency in studying, respectively (Tincani, 2004). In a recent study, Jopp and Cohen (2020) identified only four studies (Arendt, Trego, \& Allred, 2016; Cook, 2001; Hanewicz, Platt, \& Arendt, 2017; Rideout, 2017) in which students were given a choice of assignments and, in all of these studies, choice was associated with a positive outcome (e.g., increased engagement and exam scores). However, in these studies, the arrangement of procedures in order to offer choice resulted in complex point systems (e.g., Rideout, 2017), a large number of assignment choices (e.g., 59 in Arendt et al., 2016), or a vast number of different due dates (e.g., Arendt et al., 2016). To address these limitations, Jopp and Cohen kept the number of assignments available in the course and their relative weights the same as in the previous iteration of the course; however, for three of the required assignments, students could choose one of the three available assignment options. In their study, assignment 
choice increased satisfaction with the course but did not increase learning outcomes (i.e., grade) in comparison to a previous semester when the course did not include choice. Nevertheless, students indicated that they did not have a good understanding of all of the different assignment options. Furthermore, in previous studies, students did not experience both the choice and no-choice conditions; thus, individual differences between groups may have moderated outcomes (e.g., Rideout, 2017).

As noted previously, choice has had a positive impact on student engagement; however, further research on procedures that can aid in the mastery of academic content while requiring few resources is warranted. This study sought to evaluate the effects of assignment choice on student academic outcomes. To extend this line of research, this study incorporated choice of assignment (i.e., flash cards and study guides) in a simpler manner, ensured that all students experienced all experimental conditions (i.e., using an alternating-treatments design), and exposed students to both assignments prior to the onset of the study.

\section{Method}

\section{Participants and Setting}

Forty-two graduate students across two cohorts (fall 2019: $n=$ 25; spring 2020: $n=17$ ) who were enrolled in a fully online master's program participated in the current study. Most students were female $(n=39)$, and geographically, students were located around the United States. All students in each section participated in the study and were completing this course in partial fulfillment of the requirements to become a Board Certified Behavior Analyst. The course, which covered functional assessment methods, and instructor were the same across both cohorts. The course was administered via Canvas, a learning management platform previously used by the students in other courses. This was an 8-week asynchronous course wherein students were not required to meet on a certain day and time but had to progress through a module per week, and therefore the entire course, by certain deadlines. Modules were identical in setup, including a module description with learning objectives, a video introduction from the instructor, required readings, prerecorded lectures, a discussion board, and a quiz. Each component of the module was introduced in succession, meaning that completion of one task allowed the student to access the next task in the sequence. Additionally, in six out of eight modules, students completed an interactive practice assignment.

\section{Materials}

Materials included instructor-designed practice assignments (i.e., flash cards, study guides) developed using the online website GoConqr (www.goconqr.com). The flash cards and study guides covered the same subject matter and content areas (e.g., key terms and definitions), and both required approximately $15 \mathrm{~min}$ of the instructor's time to develop. The practice assignments were embedded into Canvas and were presented either concurrently (i.e., choice condition) or in isolation (i.e., no-choice condition).

\section{Dependent Variables}

Dependent variables included student academic performance and preference of assignment format. Student academic performance consisted of the average score of all students per module quiz. Quizzes were worth a total of 20 points, and each consisted of scenario-based, multiple-choice, and shortanswer questions, which were graded using an instructordeveloped rubric. Student preference of assignment format was determined by the proportion of students who selected to complete each of the assignments during choice conditions.

\section{Experimental Design and General Procedures}

A repeated-measures with an embedded alternatingtreatments design was employed to compare student performance across conditions. To mitigate any foreseen testing or sequence effects, treatment conditions were counterbalanced across cohorts and included choice, no-choice, and noassignment (i.e., control condition) conditions. Across all conditions, students completed assigned readings, viewed the module lecture, and participated in the discussion board. Then, they either completed a practice assignment and a quiz (e.g., choice and no-choice conditions) or went straight from the discussion board to the quiz (e.g., no-assignment condition). When a practice assignment was available (choice and no-choice conditions), students were instructed to dedicate at least $10 \mathrm{~min}$ to the assignment, and they could complete the assignment as many times as desired until they reached a score of $100 \%$. To receive full credit (i.e., 20 points), students were required to submit a screenshot of the score received, which also included the time spent on the assignment; thus, if a screenshot was not submitted and/or showed that students had not spent $10 \mathrm{~min}$ on the assignment, the students received zero points.

\section{Exposure Phase}

Students received instructions on the completion of each assignment type and completed an example of each assignment. However, these assignments covered content related to the syllabus and course structure. This exposure phase was implemented to give students the opportunity to experience both types of practice assignments prior to allowing them to choose between the two. 


\section{Choice Condition}

In the choice condition, students had the option to select one assignment to complete, either flash cards or a study guide. The Canvas function Mastery Paths was utilized to present the choice of assignments. First, students selected "true" or "false" in response to a pledge statement (i.e., "I have completed all readings for this module, viewed the lecture, and participated in the discussion board."). Following submission of a "true" response, students were given a choice between the two practice assignments. Upon the student's selection of an assignment, the other option was no longer available. The selection of "false" in response to the pledge statement would redirect the student to the start of the module; however, no students selected "false" throughout the course of the study.

\section{No-Choice Condition}

In the no-choice condition, an assignment, either flash cards or a study guide, was assigned to the students by the instructor. There was no pledge statement, but all other components remained the same as in the choice condition.

\section{No-Assignment Condition}

In the no-assignment (i.e., control) condition, there was no pledge statement or practice assignment available for students to complete and, therefore, no points available. All other components remained the same as in the choice condition.

\section{Procedural Fidelity}

To assess procedural fidelity, a research assistant reviewed the Canvas page and recorded whether each student completed all components of each module (i.e., completing assigned readings, viewing lectures, and participating in the discussion board) in the prescribed sequence and prior to accessing the module assignment (choice and no-choice conditions only). In addition, during the choice and no-choice conditions, data were also collected on whether each participant completed only one practice assignment. Procedural fidelity was obtained for $100 \%$ of modules across both cohorts, and the average procedural fidelity score was $100 \%$. It is important to note that data from Cohort 1 Module 1 are excluded from the procedural fidelity scores and the average quiz score across conditions because 16 of 25 students completed both the flash card and study guide assignments. Subsequently, procedural modifications were made.

\section{Results}

Student average quiz scores were highest in the choice condition for both cohorts, with a mean of $17.29(S D=2.79, n=99)$ across cohorts (see Table 1 and Fig. 1). Although student performance was slightly higher in the choice condition compared to the no-choice $(M=16.65, S D=2.62, n=123)$ and no-assignment $(M=17.00, S D=1.83, n=82)$ conditions, the differences in performance between conditions, as well as relative differences between conditions, were not statistically significant for any pairwise comparison (all $p>16$ ). A oneway analysis of variance revealed no significant differences in mean performance scores between conditions, $F(2,301)=$ $1.87, p=.157$. Indeed, no two conditions revealed statistically significant differences between mean quiz scores when follow-up Benjamini-Hochberg pairwise comparisons were used ( $p_{\text {choice vs. no choice }}=.17, p_{\text {choice vs. no assignment }}=.43, p_{\text {no }}$ choice vs. no assignment $=.43$ ). Further, relative gains between conditions also revealed no statistically significant pairwise differences between conditions when comparing normalized gain scores $\left(\left[M_{\text {post }}-M_{\text {pre }}\right] / S D\right)$ between conditions $\left(p_{\text {choice vs. }}\right.$ no choice $=.28, p_{\text {choice vs. no assignment }}=.73, p_{\text {no choice vs. no }}$ assignment $=.21)$. Similarly, a comparison between the noassignment (control) condition and the remaining two conditions using planned contrasts revealed no statistically significant differences in mean performance $(t=.24, p=.810)$. The quiz scores for each module are presented in Table 1. For Cohort 2, the no-assignment condition resulted in a higher average quiz score $(M=16.85, S D=2.06, n=34)$ compared to the no-choice condition $(M=15.4, S D=2.58, n=51)$.

The frequency of students' selection between the two practice assignment modalities (e.g., student preference of assignment format) also yielded negligible differences. Across both cohorts, in $51.5 \%$ (49 of 101) of opportunities, students chose to complete flash cards, and in $48.5 \%$ (52 of 101) of opportunities, students chose to complete the study guide during choice conditions. The difference between these proportions was not statistically significant at conventional levels $\left(\chi^{2}=\right.$ $.181, p=.67)$. However, individual data indicate that certain students often chose the same assignment across modules (data are available upon request).

\section{Discussion}

In this study, choice was designed in a simplified manner compared to previous research, thus increasing the feasibility of implementation for instructors. In addition, the influence of individual differences on mean values was minimized by employing an alternating-treatments design. In the current study, providing students with a choice of assignment improved performance only slightly and, ultimately, did not have any negative effects. Furthermore, based on the aggregate data, students did not show a preference for a particular assignment; this is not consistent with the findings of previous research (e.g., Jopp \& Cohen, 2020) in which a large portion (48\%-88\% across the three opportunities) of students selected 
Table 1 Average quiz scores for each module

\begin{tabular}{lllllllll}
\hline Cohort & M1 & M2 & M3 & M4 & M5 & M6 & M7 \\
\hline 1 & & $16.25(\mathrm{NC})$ & $16.71(\mathrm{NA})$ & $16.83(\mathrm{C})$ & $17.50(\mathrm{NA})$ & $17.21(\mathrm{NC})$ & $18.54(\mathrm{C})$ & $19.12(\mathrm{NC})$ \\
2 & $15.71(\mathrm{NC})$ & $17.41(\mathrm{C})$ & $13.74(\mathrm{NC})^{\mathrm{a}}$ & $16.12(\mathrm{NA})$ & $16.76(\mathrm{NC})$ & $15.29(\mathrm{C})$ & $17.59(\mathrm{NA})$ & $18.06(\mathrm{C})$ \\
\hline
\end{tabular}

Note. Data were excluded for Cohort 1, Module (M) 1 as several students completed both assignments (intended to be choice condition). C = choice; FC = flash cards $; \mathrm{NA}=$ no assignment $\mathrm{NC}=$ no choice; $\mathrm{SG}=$ study guide.

${ }^{\mathrm{a}}$ The start of the COVID-19 pandemic, March 2020.

the same assignment. However, as noted previously, some students often chose the same assignment across modules. This may be the case, as previous studies have identified a relationship between students' approach to learning and their preference for differing assessments (Gijbels \& Dochy, 2006). It is also likely that the selection of a particular assignment is correlated with the response effort associated with each assignment format, a hypothesis partially supported by Jopp and Cohen (2020).

Related to response effort, previous studies have noted that a limitation of providing the choice of assignments to students is that it results in the instructor spending more time creating and grading assignments (Arendt et al., 2016; Hanewicz et al., 2017). The current study avoided this issue by providing students with fewer choices of assignments, an unlimited number of attempts to complete each assignment, and designating grades as either complete or incomplete.

Given the shortage of research evaluating effective instructional practices for online learning environments, the increase in online instruction due to the COVID-19 pandemic, and our inconclusive results regarding the use of choice in higher

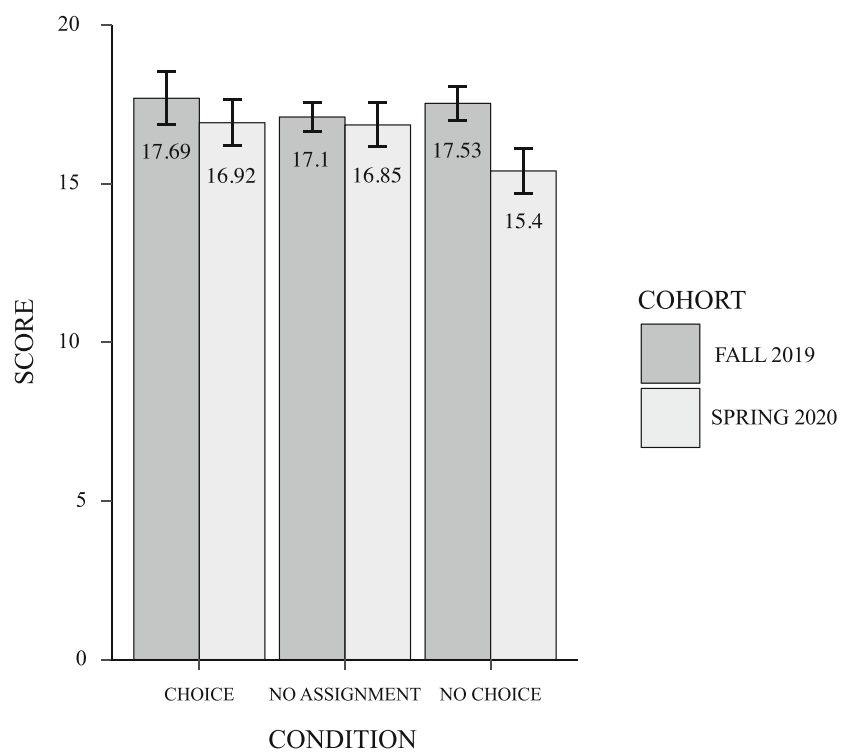

Fig. 1 Average cohort performance across conditions. Note. Bars represent $95 \%$ confidence intervals education learning, additional research in this area is needed. Future studies could evaluate the impact of the type of assignment available and student preference for assignments based on grades, as well as choice, in combination with other instructional practices (e.g., differentiated instruction). In this study, the Mastery Paths function allowed for the choice of assignment, but this function may also benefit students in other ways. For example, students could receive choices of different assignments (e.g., short Assignment 1 or short Assignment 2; long Assignment 3 and short Assignment 1) based on their scores on a pretest quiz. ${ }^{1}$ With this modification in the design of a course, differentiated instruction and choice of assignment could be automatically programmed into the course structure, promoting the involvement of LCT (Weimer, 2013); however, additional research is needed.

This study is not without limitations. As previously mentioned, data from Cohort 1's Module 1 were excluded because students completed both assignments due to a procedural error in setting up the module. This issue was resolved but required the addition of a question (i.e., pledge statement); however, this pledge statement was not present in all conditions. Furthermore, for Cohort 2, the no-assignment condition resulted in higher average quiz scores compared to the nochoice condition (e.g., control condition). This may have been the case because Module 3 (a no-choice condition) for Cohort 2 was in March 2020, at the start of the pandemic. Given that the stay-at-home order may have impacted childcare and job security and added additional stressors for the students, the lower quiz score on this module may be a reflection of the added environmental changes and not directly an effect of the no-choice condition. Additionally, in both cohorts, performance on the end-of-module quizzes improved across the 8 weeks, perhaps because students learned what to expect during the quizzes and to identify the most relevant information from lectures, readings, and practice assignments. Future studies may attempt to replicate these procedures, but with the randomization of entire cohorts experiencing only one condition, followed by a comparison of the performance of each cohort across conditions. To address other limitations of the

\footnotetext{
${ }^{1}$ A task analysis describing the steps necessary to use the Mastery Path function in Canvas is available under Supplemental materials.
} 
current study, future studies should assess the acceptability of the conditions (i.e., social validity) and evaluate variables (e.g., preference, response effort) that impact the selection of assignment.

Supplementary Information The online version contains supplementary material available at https://doi.org/10.1007/s40617-021-00566-8.

\section{Declarations}

Conflict of Interest We have no conflicts of interest to disclose.

\section{References}

Arendt, A., Trego, T., \& Allred, J. (2016). Students reach beyond expectations with cafeteria style grading. Journal of Applied Research in Higher Education, 8(1), 2-17. https://doi.org/10.1108/jarhe-032014-0048.

Behavior Analyst Certification Board. (2021). Verified course sequence directory. Association for Behavior Analysis International. Retrieved January 18, 2021 from https://www.abainternational.org/ vcs/directory.aspx
Cook, A. (2001). Assessing the use of flexible assessment. Assessment and Evaluation in Higher Education, 26(6), 539-549. https://doi. org/10.1080/02602930120093878.

Gijbels, D., \& Dochy, F. (2006). Students' assessment preferences and approaches to learning: Can formative assessment make a difference? Educational Studies, 32(4), 399-409. https://doi.org/10. 1080/03055690600850354.

Hanewicz, C., Platt, A., \& Arendt, A. (2017). Creating a learner-centered teaching environment using student choice in assignments. Distance Education, 38(3), 273-287. https://doi.org/10.1080/01587919. 2017.1369349.

Jopp, R., \& Cohen, J. (2020). Choose your own assessment—Assessment choice for students in online higher education. Teaching in Higher Education. https://doi.org/10.1080/13562517.2020.1742680. Advance online publication.

Rideout, C. (2017). Students' choices and achievement in large undergraduate classes using a novel flexible assessment approach. Assessment and Evaluation in Higher Education, 43(1), 68-78. https://doi.org/10.1080/02602938.2017.1294144.

Tincani, M. (2004). Improving outcomes for college students with disabilities: Ten strategies for instructors. College Teaching, 52(4), 128-133. https://doi.org/10.3200/CTCH.52.4.128-133.

Weimer, M. (2013). Learner-centered teaching: Five key changes to practice (2nd ed.). San Francisco: Wiley.

Publisher's Note Springer Nature remains neutral with regard to jurisdictional claims in published maps and institutional affiliations. 